\title{
EL CONCEPTO DE IGUALDAD ANTE EL MERCADO
}

\section{Carlota Solé}

Universidad Autónoma de Barcelona

\section{RESUMEN}

Después de examinar el concepto de igualdad desde el punto de vista sociológico, en la realidad social del capitalismo avanzado y en el superado socialismo real, se analiza críticamente el papel del Estado como mecanismo igualitario o redistribuidor (de rentas, de privilegios, de recursos, de habilidades, etc.).

\section{EL CONCEPTO DE IGUALDAD EN EL PENSAMIENTO SOCIOLOGICO}

Desde el punto de vista sociológico, el concepto de igualdad debe considerarse en relación a la superación de la desigualdad social, fenómeno inevitable y universal. En todas las sociedades, avanzadas o bien del Tercer Mundo, capitalistas o de socialismo real, se da la circunstancia y el hecho de que los hombres están situados desigualmente en posiciones sociales diferentes. Aparte de las diferentes gradaciones según la propiedad y la no propiedad, la dominación y la subordinación, existen múltiples diferencias de rango tan sutiles y profundas que uno se pregunta sobre la imposibilidad de alcanzar la igualdad social.

Las preguntas que surgen inmediatamente son: ¿por qué existen desigual- 
dades entre los hombres? ¿Cuáles son las causas? ¿Puede ser reducida o abolida completamente? $\mathrm{O}$ bien: ¿es un mal necesario, un elemento inevitable y quizá imprescindible en la estructura de la sociedad humana? Desde el ángulo de la potencial superación de la desigualdad podemos preguntarnos: ¿por qué es deseable la igualdad social? ¿Cómo esperan los hombres beneficiarse de ella? ¿Qué han de hacer los hombres con tal de promover la igualdad y qué han de rechazar con tal de alcanzarla y mantenerla?

Históricamente, éstas son las primeras preguntas y cuestiones que se planteó la sociología en su origen después de asimilar las influencias de las dos primeras grandes revoluciones modernas, la francesa y la industrial. Los intentos sistemáticos de respuesta a estas cuestiones han constituido un cuerpo enormemente importante de pensamiento social y teoría sociológica. El problema de la desigualdad constituye uno de los núcleos fundamentales de investigación sociológica desde el estudio de sus orígenes en el siglo XVIII, la formación de las clases por parte de los pensadores sociales en el siglo XIX, hasta las teorías de la estructura o estratificación social en el siglo XX.

Los criterios o conceptos clave para explicar la desigualdad han sido el de la propiedad (de riqueza o de medios de producción) (A. Smith, K. Marx), estatus (M. Weber), poder y autoridad (R. Dahrendorf), prestigio (T. Parsons), privilegio (G. Lenski), entre otros. La esfera en la que se dan las diferenciaciones sociales según estos criterios es la de la producción o la de distribución de bienes y servicios (incluso, la fuerza de trabajo), en el seno de una formación económico-social (K. Marx, 1972, 1976), una sociedad (M. Weber, 1970; G. Lenski, 1966), una asociación imperativamente coordinada (R. Dahrendorf, 1957), un sistema social (T. Parsons, 1966). La unidad estratificacional básica es la de clase social, grupo-de-estatus, grupo-de-intereses o estratos sociales; y las relaciones entre ellas serán de lucha abierta, de dominación-subordinación, de conflicto institucionalizado o de reequilibrio sistémico.

Este esquema es aplicable a las sociedades capitalistas y a las socialistas. Ahora bien, si consideramos la igualdad como la superación de la desigualdad, ha sido el capitalismo el sistema de producción, sistema de organización social y régimen político el que tradicionalmente o históricamente se ha tomado como impedimento para asumir la plena igualdad de las personas, los individuos o los ciudadanos. El elemento de corrección de este obstáculo y las imputaciones que se le aplican ha sido el de la igualdad de oportunidades. Este principio capitalista contrasta con el esgrimido a las sociedades socialistas de la igualdad según las necesidades de cada uno. La igualdad de oportunidades significa que cada uno, independientemente de sus orígenes, puede tener la misma posibilidad, bajo la condición de poseer las capacidades y habilidades adecuadas, de alcanzar los lugares más elevados en la escala ocupacional y en la estructura social. El principio socialista de "a cada cual según sus necesidades» responde a la posibilidad idéntica o semejante para todo individuo de obtener los méritos adecuados para alcanzar las posiciones de estatus (que comportan 
determinados privilegios) más elevadas en la escala ocupacional y la estructura social (S. Ossowski, 1966).

La igualdad se configura a partir de ambos principios. La sociedad capitalista, el ejemplo más notorio de la cual son los Estados Unidos de América, pretende dar la imagen de sociedad igualitaria por la superación de la división de clases sociales, a través de la movilidad social vertical garantizada por las oportunidades ilimitadas de avance y promoción sociales. En la sociedad socialista la igualdad se fundamenta en la desaparición de las clases sociales, aunque se mantengan diferencias en la participación en la renta y distribución de privilegios. A nivel teórico, el concepto de clase social está más próximo de los grupos sociales que detectan diferentes fuentes de ingresos o rentas (A. Smith, 1961) que no del marxista, aplicable en rigor a las sociedades capitalistas.

\section{IGUALDAD DE OPORTUNIDADES, IGUALDAD DE RESULTADOS}

La igualdad social se manifiesta en la igualdad de oportunidades, es decir, la situación en la que toda persona es capaz de progresar en términos de riqueza y estatus social de acuerdo con sus capacidades y sus méritos. Se manifiesta también en la igualdad de resultados como situación en la que toda persona llega al mismo nivel de riqueza y estatus que sus semejantes, sin tener en cuenta los medios para obtener este fin.

La cuestión se plantea para las sociedades capitalistas en evaluar si el orden económico basado en la propiedad privada y la libre utilización de la riqueza promueve u obstaculiza las potencialidades y habilidades de sus miembros y permite o no resultados parecidos para todos. La realidad es la de la persistencia de la distribución desigual de incentivos y motivaciones proporcionales al esfuerzo y habilidades incorporados a cualquier actividad que realicen los miembros de una sociedad capitalista. Las sociedades de socialismo real no han conseguido tampoco anular los incentivos de tipo económico y social (salarios, privilegios) para hacer frente a problemas de productividad y eficiencia.

Esto nos lleva a pensar que la igualdad de oportunidades y de resultados deben de considerarse como especificaciones de la justicia distributiva [D. Winthrop a P. Berger (ed.), 1987], además del deseo legítimo de toda persona a desarrollar sus capacidades (o alguna de sus capacidades) en conseguir riqueza y estatus, que en una sociedad capitalista dependen del mercado. Las capacidades y habilidades reconocidas y recompensadas en una sociedad serán las que den resultados y consecuencias que sirvan a las necesidades de todo tipo y gratifiquen los deseos ilimitados de los individuos. Este ideal, sin embargo, se materializa en las necesidades y deseos dominantes en una sociedad, es decir, los universalizados por una clase social o grupo dominante, si no hegemónico. Es por ello que sólo en teoría pueda sostenerse que los individuos desean riqueza y estatus como contrapartida a la implementación de las pro- 
pias capacidades y habilidades. Es por ello también que la igualdad de resultados es problemática; más que ser iguales en riqueza y estatus, los individuos quieren llegar a detectar más riqueza y más alto nivel de estatus, de acuerdo con la actividad correspondiente a la ocupación que tengan. Si todas las ocupaciones fueran igualmente honorables (en términos de estatus) y remuneradas (en términos de riqueza), nadie tendría motivación alguna por realizar una tarea u otra. El honor o estima social que se encuentra en la base de una posición de estatus determinada (M. Weber, 1970) presupone la desigualdad social; no conduce a la igualdad. Igualmente, la igualdad en riqueza se condiciona a la dignidad de los seres humanos en poder escoger y decidir sobre la forma de vida que deseen. En la práctica, este ideal se encuentra condicionado por la realidad del orden socioeconómico.

A fin de paliar los efectos de este condicionamiento en la consecución de la igualdad, desde el punto de vista de la democracia liberal se ha tomado la redistribución de la renta como un instrumento corrector de las modalidades de dicotomía fundamentada en la distribución desigual de privilegios o repartición de beneficios. Nos referimos a las dicotomías entre ricos y pobres (divididos según la posesión de riqueza), gobernados y gobernantes (según los criterios de distribución desigual de poder y autoridad), empleados y empleadores (de acuerdo con una relación de explotación de un grupo sobre el otro) (S. Ossowski, 1966). El Estado de bienestar ha tenido un papel protagonista en implementar las políticas redistributivas hacia la igualdad.

Actualmente, las dicotomías mencionadas se complementan en las sociedades avanzadas con la que se puede establecer según criterios raciales o étnicos, aparte de la variable género. Así, las disparidades en la distribución de la renta se explican por las desiguales oportunidades en el mercado de trabajo y vida social de los diversos grupos étnicos. Ahora bien, las políticas educativas y antidiscriminatorias, en general, para disminuir las desigualdades de ingresos y de oportunidades, no ponen en cuestión la convicción de que las rentas percibidas dependen del esfuerzo incorporado individualmente en una actividad y no deben ser asignadas por el gobierno. El principio básico del capitalismo liberal, a saber, que la propiedad de los individuos es genuinamente privada y que pueden conseguir todo aquello que hayan legalmente ganado con su esfuerzo y trabajo, excepto la porción de su riqueza o ingresos con los que han de contribuir (en forma de impuestos) a cubrir los gastos públicos, no se pone en cuestión.

No obstante, la idea de redistribución de la renta no considera la frontera entre la esfera privada y la pública. Si el gobierno tiene el poder para determinar la distribución de la renta, los individuos sólo podrán argüir sus derechos y reclamaciones legítimas sobre los recursos que el gobierno les atribuya, dejando que los objetivos públicos cuenten con su colaboración como contribuyentes. Esta situación es perfectamente compatible con el medio de producción capitalista avanzado, basado en la eficiencia del mercado y el rol de los incentivos individuales con el fin de maximizar la productividad y la riqueza [M. F. Plattner, 1987, a P. Berger (ed.)]. 
La eficiencia económica y la libertad individual como valores característicos de una sociedad capitalista liberal contribuyen a la igualdad económica y social si se resuelve la contradicción entre la igualdad de derechos políticos y la existente desigualdad de rentas o ingresos, bajo el criterio de la igualdad de oportunidades. Este criterio sólo puede imponerse si se intenta racionalizar el Estado de bienestar, desde el punto de vista de la eficiencia económica, para alcanzar la legitimación de la redistribución de la renta, en detrimento de la autonomía y libertad del individuo. Así se puede conseguir reducir las desigualdades económicas y sociales.

Los valores de la eficiencia y la libertad no comportan, sin embargo, una situación real ni un valor absoluto de igualdad en las sociedades capitalistas liberales. En los países de socialismo real se presuponía que existía más igualdad de hecho pero menos libertad, de la misma forma que se acepta convencionalmente que el precio de la libertad bajo el capitalismo es el de la relativa desigualdad existente. Hay que hablar, pues, de igualdad relativa en el sentido histórico-comparativo e intersocietal, tanto en términos de riqueza y renta como de nivel y calidad de vida de los miembros de una sociedad.

Así, la comparación entre sociedades capitalistas y socialistas debe complementarse con la consideración de los países del Tercer Mundo, en lo referente a las condiciones de vida y de trabajo de las diferentes clases sociales o grupos en su seno. Es, por ejemplo, verosímil que el nivel y calidad de vida de las clases trabajadoras de los Estados Unidos de América, de acuerdo con diversos indicadores de bienestar individual, sea más elevado que el de otros lugares del mundo. De aquí se podría deducir que un país capitalista como el mencionado tiene la suficiente capacidad de desarrollo económico (innovaciones tecnológicas aplicadas a sectores punteros de la economía, reorganización del trabajo, capacidad productiva, etc.) para producir un efecto igualitario en la sociedad. La crítica inevitable a esta posición considera central la relación de dependencia del desarrollo del capitalismo avanzado y el subdesarrollo que afecta a muchos países del mundo.

\section{EL PAPEL DEL MERCADO}

Por otro lado, el efecto de las políticas redistributivas por parte de los gobiernos de algunos países occidentales no ha conducido a la desaparición total de las desigualdades sociales, a pesar del aumento sustancial, en términos relativos, de la riqueza y de la renta; además de los costos políticos de la democracia liberal. Las diferencias entre los estratos de la estructura social, según los criterios de riqueza, estatus, poder, autoridad, prestigio o privilegio, persisten de forma compatible con la movilidad social garantizada por el credo de la igualdad de oportunidades. De hecho, la movilidad social no se correlaciona positivamente con la igualdad basada en una distribución igualitaria de la riqueza y la renta. 
El mercado se ha considerado el mecanismo igualitario más eficiente al garantizar la movilidad ocupacional y social, bajo las condiciones de un orden capitalista ideal. Hoy se detectan en las sociedades avanzadas elementos corporatistas (Ph. C. Schmitter, 1982) que comportan factores de mercado y de nomercado, por la incorporación en la vida social de las asociaciones, además del Estado, los sindicatos y otros grupos de intereses representados institucionalmente, incorporación que ha modificado la dinámica de mercado capitalista. Se considera que un nuevo orden social basado en la asociación corporativa o corporación (en un sentido más laxo del término, confusamente utilizado, pues describe un tipo especial de institución de mercado) ha emergido en contraste con los órdenes sociales fundamentales en la comunidad, el mercado y el Estado. Estos órdenes se guían por los principios de la solidaridad espontánea, la competencia dispersa y el control jerárquico (W. Streeck y Ph. C. Schmitter, 1985). La consecución de la igualdad (o, en rigor, de un más elevado nivel de igualdad) es entonces aún más problemática. En el momento en que el Estado ejerce la expansión intervencionista en la economía de mercado, las asociaciones se consideran disfuncionales por parte de las otras instituciones interrelacionadas. Las modernas asociaciones de intereses tienden a convertirse en alienadas de los valores de la comunidad. Desde el punto de vista político, las asociaciones se consideran como un impedimento a la democracia liberal y a las prácticas parlamentarias, al dirimirse el conflicto a través de los pactos y acuerdos sociales y económicos. Queda por saber si la existencia creciente de asociaciones corporativas en las sociedades avanzadas conducirá a un orden social más igualitario, o bien más elitista y no-democrático.

En el contexto internacional actual tan cambiante, si del nivel de la interacción entre individuos o grupos pasamos al nivel del orden social, es decir, si intentamos explicar cómo una multitud de individuos independientes con motivaciones e intereses diversos conjugan sus expectativas y esfuerzos produciendo o reproduciendo el «orden social» (utilizando el lenguaje de los clásicos de la Sociología), en las sociedades industriales avanzadas, las asociaciones juegan un papel central como fuente del orden social, más allá de los vínculos de la comunidad, el Estado y el mercado. Obviamente, la combinación o amalgama entre la comunidad, el Estado y el mercado, rigiéndose por los principios de la solidaridad espontánea, la competencia dispersa y el control jerárquico, está presente en toda sociedad avanzada en la que la base institucional de las asociaciones, rigiéndose por el principio de concertación organizativa, acaba caracterizando a un tipo de sociedad basada en un sistema de intereses negociados entre los diversos grupos de intereses y en la que el conflicto social se dirime (con alguna excepción esporádica) a través de la negociación (W. Streeck y Ph. C. Schmitter, 1985, cap. 1). Las asociaciones proporcionan la base para el orden social y contribuyen, por la acción de la concertación organizada, a crear el sistema de intercambio de compensaciones negociadas, característico de las sociedades modernas actuales.

Esta percepción contrasta con la idea tradicional de las asociaciones como 
fuente del desorden social. En la historia de las sociedades industrializadas, que han desarrollado un sistema democrático de elecciones en todos los niveles de la vida social, la penetración del mercado en las comunidades del siglo XIX significa un gran paso hacia adelante en la ruptura de los antiguos vínculos sociales protagonizados y representados precisamente por asociaciones (de trabajadores: gremios; de creyentes: iglesia, etc.). Junto con el intervencionismo de un Estado potente, en el siglo XX se configuran las modernas economías de mercado. En ese momento, las asociaciones tienen también una percepción contraproducente para el desarrollo del Estado moderno, omnipresente y fuerte. La existencia en Europa de tres regímenes fascistas (corporatismo autoritario) corrobora esta apreciación. En cualquier caso, hasta principios de la década de los ochenta, una vez contrastada empíricamente (Ph. C. Schmitter, 1982; C. Crouch, 1979; S. Berger, 1981) la importancia que toman las asociaciones en las economías de mercado y sociedades avanzadas, las asociaciones son consideradas en los análisis teóricos e históricos como disfuncionales para el orden social. Se contemplan como cárteles y, por tanto, como causa de una asignación insuficiente de recursos, o bien son tratadas como obstáculos para el ejercicio de la democracia liberal.

En los últimos veinte años, en las sociedades avanzadas se genera y desarrolla una enorme variedad de asociaciones, instituciones y organizaciones que, a través de su acción organizada de intereses, fundamentada en el principio de interacción y asignación de recursos (materiales e inmateriales) entre diversos conjuntos o grupos de intereses, más o menos privilegiados según su posición ante el mercado, constituye una base adicional y nueva del orden social corporatista. Los actores sociales principales (clases sociales, asociaciones profesionales, asociaciones sectoriales, asociaciones territoriales, de empresarios, sindicatos, etc.) se definen por su afán común de conseguir objetivos y defender intereses funcionalmente definidos. El principio rector es el de establecer compromisos, negociaciones y pactos sobre los actores sociales que mutuamente se reconocen como representantes de los intereses que esgrimen. El orden corporatista, para distinguirlo del corporativo (fascista), se fundamenta en la interacción en el seno y entre asociaciones complejas interdependientes; sin detrimento de establecer relaciones de interacción secundarias externas (con otros interlocutores como, por ejemplo, los individuos que no son miembros de la asociación, con el Estado o la Administración, etc.).

Frente al mercado, las asociaciones no actúan como actores sociales independientes, al igual que los competidores (en el seno del mercado), sino que son y actúan de forma interdependiente, siguiendo estrategias colectivas, y de forma contingente según las circunstancias. En cualquier caso, las acciones de las asociaciones pueden tener efectos previsibles y al mismo tiempo determinados por la satisfacción de los intereses de otras colectividades organizadas.

Esto induce a establecer pactos y acuerdos de relativa estabilidad. Para conseguir este estadio, las asociaciones (de intereses) han de tener capacidad de representación, mecanismos de control sobre la conducta de sus miembros y el 
monopolio en el estatus de intermediarios entre los diversos sectores económicos, territorios, clases sociales, que representan (W. Streeck y Ph. C. Schmitter, 1985, p. 11). En la medida que las asociaciones (de intereses) se fragmentan en competidores en el mercado, rivalizando para obtener más recursos o captar mayor número de miembros, mayor cuota en la distribución de mercancías, de bienes y servicios, dependiendo de la afiliación voluntaria o de la autoridad estatal, no existirá un orden social corporatista. Pero persistirá, tal vez, la posibilidad de mayor igualdad de oportunidades extensiva a un mayor número de personas en un orden social propio de sociedades heterogéneas (M. Hechter, D. Friedman y S. Kanazawa, 1992).

Es por ello pertinente hablar, por último, del mercado como mecanismo de control democrático (H. K. Colebatch, 1994, pp. 12-13). En un mercado competitivo la gente puede elegir el bien o servicio (material o inmaterial) que desea. Dada la multitud y variedad de preferencias e intereses de las personas, la elección individual queda garantizada por la acción del mercado al que confluyen compradores y vendedores, proveedores y clientes, actores sociales interactuando e intercambiando bienes y compensaciones. El control democrático se lleva a cabo no a través de la acción colectiva, sino a través de la elección agregada de los individuos, que pueden escoger alternativamente entre varios proveedores. Aquellos proveedores que concuerden con las preferencias de los compradores tendrán éxito, y aquellos que no coincidan, fracasarán. De existir una asociación representativa de los intereses de los individuos, éstos serán libres de permanecer o retirarse de ella, según estén o no de acuerdo con las actividades que la asociación lleva a cabo. La retirada o no entrada advertirá a la asociación de la necesidad de un cambio de estrategia para lograr una mayor representatividad y legitimidad frente a sus afiliados, presentes y potenciales. Advertirá también de la potencial competencia de otras asociaciones. Ahí penetra el mercado como instrumento de control democrático: la organización o asociación intentará identificar, con precisión, las preferencias de sus clientes, afiliados, miembros en general, para seguir contando con su fidelidad y mantener su presencia y reconocimiento. Los miembros de una asociación, sin embargo, sólo cuentan con la opción de afiliarse o no afiliarse a ella. Si se afilian, con el fin de obtener los bienes y servicios deseados, o alcanzar los objetivos que sólo colectivamente pueden conseguirse, deberán aceptar aspectos y actuaciones de la asociación que no les conciernen directamente. Así, a pesar de la aparente disolución del individuo en la asociación, la cesión por ambas partes puede garantizar el control democrático, y en última instancia la igualdad ante el mercado, o, parafraseando a Touraine, no sólo la atribución a todos los ciudadanos de los mismos derechos, sino como medio de compensar las desigualdades sociales (A. Touraine, 1994, p. 53). 


\title{
BIBLIOGRAFIA
}

Berger, P. L. (ed.) (1987): Modern Capitalism, London: Hamilton Press.

Berger, S. (1981): Organizing Interests in Western Europe, Cambridge: Cambridge University Press.

Colebatch, H. R. (1994): "The democratic control of business: Market state and Community», XVI World Congress of the International Political Science Association, Berlín, agosto.

Coleman, J. S., y Fararo, Th. (eds.) (1992): Rational Choice Theory, London: Sage.

Crouch, C. (1979): State and Economy in Contemporary Capitalism, London: Croom Helm.

Dahrendorf, R. (1957): Class and Class conflict in Industrial Society, London: Routledge and Kegan Paul (1949).

HeCHTER, M., et alii (1992): "The attainment of global order in heterogeneous societies», en J. S. Coleman y Th. Fararo (eds.).

Lehmbruch, G., y Schmitter, Ph. C. (eds.) (1982): Patterus of Corporatist Policy Making, London: Sage.

Lenski, G. (1966): Power and Privilege, Princeton University Press.

MARX, K. (1972): Capital, London: Lawrence and Wishart.

- (1976): 18 Brumario, Madrid: Alberto Corazón.

OssowsKI, S. (1966): Estructura de clases y conciencia social, Barcelona: Ediciones 62 (1963).

PARSONS, T. (1966): Estructura y Proceso en las sociedades modernas, Madrid: CSIC.

Plattner, M. F. (1987): «The New Egalitarianism», en P. L. Berger (ed.).

SCHMitTer, Ph. C. (1982): «Reflections on Where The Theory of Neocorporatism has gone and Were the Praxis of Neocorporatism may be going», en G. Lehmbruch y Ph. C. Schmitter (eds.).

SMith, A. (1961): Indagación acerca de la naturaleza y las causas de la riqueza de las naciones, Madrid: Aguilar.

Streeck, W., y Schmitter, Ph. C. (eds.) (1985): Private Interest Government. Beyond Market and State, London: Sage Publ.

Touraine, A. (1994): ¿Qué es la democracia?, Madrid: Temas de Hoy.

Weber, M. (1970): Economy and Society, London: Routledge and Kegan Paul (1918, 1920).

Winthrop, D. (1987): «Why Equality», en P. L. Berger (ed.).

\begin{abstract}
After examining the concept of equality from a sociological standpoint and from the perspective of the social reality of advanced capitalism and practically-defunct real socialism (ie, communism), this paper presents a critical analysis of the role of the State as an egalitarian or redistributive mechanism (of income, privileges, resources, abilities, etc.).
\end{abstract}

